\title{
Polypectomy techniques among gastroenterologists in Norway - a nationwide survey
}

\section{(ㄷ)(1) $\odot$}

\author{
Authors
}

Ina B. Pedersen ${ }^{1,2}$, Magnus Løberg ${ }^{2,3}$, Geir Hoff ${ }^{2,3,4,5}$, Mette Kalager ${ }^{2,3}$, Michael Bretthauer ${ }^{2,3,6}, \emptyset$ yvind Holme $^{1,2}$

Institutions

1 Department of Medicine, Sørlandet Hospital Kristiansand, Kristiansand, Norway

2 Institute of Health and Society, Clinical Effectiveness Research Group, University of Oslo, Oslo, Norway

3 Department of Transplantation Medicine and K. G. Jebsen Colorectal Cancer Research Center, Oslo University Hospital, Oslo, Norway

4 Department of research, Telemark Hospital, Skien, Norway

5 Cancer Registry of Norway, Oslo, Norway

6 Frontier Science, Boston, Massachusetts, United States

submitted 14.12.2017

accepted after revision 19.3.2018

\section{Bibliography}

DOI https://doi.org/10.1055/a-0607-0727 |

Endoscopy International Open 2018; 06: E812-E820

(c) Georg Thieme Verlag KG Stuttgart · New York

ISSN 2364-3722

Corresponding author

Ina B. Pedersen, Sørlandet Hospital, Post box 416, N-4604, Kristiansand, Norway

Fax: +47 37083551

inaborgenheimpedersen@gmail.com

\section{ABSTRACT}

Background and study aims Incomplete polyp removal has been estimated to cause $27 \%$ of all colorectal cancers detected soon after colonoscopy. There is limited information regarding polypectomy techniques among endoscopists. The article is a nationwide survey of polypectomy techniques among Norwegian endoscopists.

Materials and methods We invited all board-certified gastroenterologists in Norway to complete a web-based questionnaire about their polypectomy technique. Inadequate polypectomy techniques were defined as using biopsy forceps for polyps larger than $3 \mathrm{~mm}$ in diameter, using hot biopsy forceps for polypectomy, and using the same electrocautery output irrespective of polyp size and morphology.

Results Twenty-six of 30 Norwegian gastroenterology departments participated in the study. A total of 119 endoscopists received the survey, and 70 (59\%) responded. Mean duration of endoscopy practice was 11.5 years, and $95 \%$ had performed more than 1,000 colonoscopies during their career. Twenty-eight endoscopists ( $40 \%$ ) used one or more inadequate polypectomy techniques: 10 (14.3\%) used biopsy forceps for removal of polyps larger than $3 \mathrm{~mm}$ in diameter, five $(7.1 \%)$ used hot biopsy for polypectomy, and 17 (24\%) used the same electrocautery output for all polypectomies. Five ( $7 \%$ ) endoscopists reported that they did not remove polyps smaller than $4 \mathrm{~mm}$.

Conclusion A substantial number of Norwegian endoscopists use inadequate polypectomy techniques. Improved training and certification of endoscopists is warranted.

\section{Introduction}

Colorectal cancer (CRC) is the third most common cancer worldwide [1], and Norway has one of the highest incidence rates of CRC in the world [2]. CRC incidence and mortality can be reduced by removal of colorectal polyps $[3,4]$.

A prerequisite for reducing CRC incidence through polypectomy is complete removal of the polyps. The proportion of incompletely resected polyps vary with size and histology of the polyp as well as with the technique used for resection [5]. Moreover, frequency of incomplete polyp resection varies widely among endoscopists [5, 6]. Approximately $20 \%$ of cancers detected after colonoscopy are caused by incomplete polypectomy [7].

Polypectomy is associated with risk of complications, of which bleeding and perforations are the most severe. Bleeding due to polypectomy occurs in $0.1 \%$ to $0.6 \%$ and perforations in $0.02 \%$ to $0.1 \%$ of colonoscopies [8]. Safe and complete polypectomy is therefore an important consideration for endoscopists and requires complex decision-making, including whether to remove the polyp, what polypectomy technique to apply (e.g. snare, forceps, use of electrocautery, level of elec- 
tric current) and if preventive measures should be undertaken to reduce the risk of complications (e.g. clipping of the stalk before removal of pedunculated polys).

Endoscopists use a variety of polypectomy techniques [ 9 , 10]. Many of them use inadequate techniques, which may translate into increased risk of complications or incomplete removal of polyps. Surveillance is recommended after polypectomy, but many endoscopists do not adhere to post-polypectomy guidelines [11-14].

We aimed to investigate whether Norwegian endoscopists used inadequate polypectomy techniques, and if they followed the national guidelines for polyp surveillance.

\section{Materials and methods}

All board-certified gastroenterologists (consultants) in Norway who perform colonoscopic polypectomies were eligible for the study. No trainees or fellows were approached. To identify eligible endoscopists, we approached 30 Norwegian hospitals with gastroenterology departments to obtain email addresses. The identified endoscopists received an electronic questionnaire by email, using commercially available online survey-software $\left(\right.$ SurveyMonkey ${ }^{\odot}$ ). If the gastroenterologists did not reply initially, two reminders were sent. The survey was conducted between April 2015 and May 2016.

The first draft of the questionnaire was made using the questionnaires from the two earlier surveys $[9,10]$ as a basis. We extended the questionnaire to allow for further evaluation of polypectomy techniques. After the first draft, we invited about 360 endoscopists (both surgeons and gastroenterologists), endoscopy assistants and fellows, to comment on the questionnaire and suggest additional items. Some questions were removed and some were added according to these suggestions. Finally, we asked seven experienced gastroenterologists to test the survey, and the final version was created based on their feedback. In the final questionnaire, we included the questions that were most relevant to assess completeness of polypectomy, complications and adherence to post-polypectomy surveillance guidelines.

The study was approved by the Norwegian Centre for Research Data, and completing the survey was considered as consent to participate in the study. The study was waived ethical approval from the regional ethics committee of South-East Norway. An English translation of the questionnaire is available in the supplementary appendix (Supplement 1).

Primary outcomes of interest were proportion of endoscopists with inadequate polypectomy technique for removal of polyps smaller than $1 \mathrm{~cm}$ in diameter, and adherence to national surveillance guidelines. We also explored whether contemporary polypectomy techniques (e.g. cold snare polypectomy) had been implemented in daily practice. There are no national guidelines for polypectomy in Norway. Based on published research and international guidelines, we therefore defined inadequate polypectomy techniques as: use of biopsy forceps for removal of polyps larger than $3 \mathrm{~mm}$, use of hot biopsy forceps (biopsy forceps with electrocautery for polypectomy), and use of the same electrocautery output (coagulation, cut or blend) irrespective of the size and morphology of the polyp to be removed. Further, we defined hot snare polypectomy as snare polypectomy with use of electrocautery and cold snare polypectomy as snare polypectomy without use of electrocautery.

The questionnaire also included questions concerning adherence to guidelines for post-polypectomy surveillance (see supplement). Norwegian post-polypectomy surveillance guidelines are identical to the guidelines issued by the European Society of Gastrointestinal Endoscopy [11].

\section{Statistics}

Descriptive statistics are presented as mean with standard deviation (SD) for normally distributed data. To assess which risk factors predict inadequate polypectomy technique and nonadherence to surveillance guidelines, we fitted univariable logistic regression models using endoscopist sex, age, experience (years of practice) and hospital category (university versus nonuniversity) as explanatory variables. Finally, we fitted a multivariable model using backward removal of variables with a Wald test $P$ values $\geq 0.05$. All analyses were conducted with Stata software version 14.2 (StataCorp, College Station, Texas, United States), and $P<0.05$ was considered statistically significant.

\section{Results}

Twenty-seven hospitals (90\%) responded to our initial invitation and 26 endoscopy department chairs provided email addresses for their eligible endoscopists. One department chair did not want to participate in the study.

The questionnaire was distributed to 119 board-certified gastroenterologists (consultants), of whom 70 (59\%) responded. There were $58(83 \%)$ men and $12(17 \%)$ women among the responders, and the mean age was 51.5 years ( $>$ Table 1 ). A total of 18 endoscopists (25.7\%) worked at university hospitals, and $52(74.3 \%)$ worked at non-university hospitals. Most endoscopists were experienced, $93 \%$ had performed more than 1000 colonoscopies, and the mean duration of endoscopy practice was 11.5 years ( $\triangleright$ Table 1 ).

\section{Inadequate polypectomy technique}

Most endoscopists (74\%) removed polyps smaller than $4 \mathrm{~mm}$ in diameter with biopsy forceps, but 5 (7\%) endoscopists did not remove polyps of this size at all ( $\triangleright$ Table 2$)$. Overall, 28 (40\%) endoscopists used one or more inadequate methods for removal of polyps smaller than $1 \mathrm{~cm}: 17$ (24.3\%) endoscopists did not adjust electrocautery output dependent on size and morphology of the polyp, five endoscopists (7.1\%) used hot biopsy forceps for polyp removal, and 10 (14.3\%) used biopsy forceps for removal of polyps $>3 \mathrm{~mm}$ ( $>$ Table 2, $>$ Fig. 1).

None of the factors we investigated (endoscopist sex, age, years of practice and hospital category) were associated with inadequate polypectomy technique. 


\begin{tabular}{|l|c|}
\hline Table 1 Characteristics of endoscopists. & $51.5(8.0)$ \\
\hline Age (years), mean (SD) & $11.5(7.6)$ \\
\hline Years in endoscopy practice, mean (SD) & \\
\hline Sex, $\mathrm{n}(\%)$ & $58(82.9)$ \\
\hline Male & $12(17.1)$ \\
\hline Female & \\
\hline Number of colonoscopies performed & $2(2.9)$ \\
\hline$<500$ & $3(4.3)$ \\
\hline $500-1000$ & $40(57.1)$ \\
\hline $1000-5000$ & $19(27.1)$ \\
\hline $5000-10000$ & $6(8.6)$ \\
\hline$>10000$ & \\
\hline Number of colonoscopies per year & $7(10.0)$ \\
\hline$<100$ & $34(48.6)$ \\
\hline $100-300$ & $29(41.4)$ \\
\hline$>300$ & \\
\hline Hospital category & \\
\hline SD, standard deviation & \\
\hline
\end{tabular}

- Table 2 Polypectomy techniques for removal of polyps smaller than $1 \mathrm{~cm}$ in diameter, stratified by size.

\begin{tabular}{|l|r|r|r|}
\hline \multirow{2}{*}{ Polypectomy method } & \multicolumn{2}{|l}{ Size } \\
\cline { 2 - 3 } & $\mathbf{1 - 3} \mathbf{~ m m}$ & $\mathbf{4 - 6} \mathbf{m m}$ & $\mathbf{7 - 9} \mathbf{m m}$ \\
\hline Do not remove & $5(7.1)$ & & \\
\hline Biopsy forceps & $52(74.3)$ & $9(11.0)$ & \\
\hline Hot biopsy & $3(4.3)$ & $2(2.45)$ & $1(1.1)$ \\
\hline Cold snare & $5(7.1)$ & $17(20.7)$ & $3(3.4)$ \\
\hline Hot snare & $4(5.7)$ & $37(45.1)$ & $47(54.1)$ \\
\hline EMR & $1(1.5)$ & $15(18.3)$ & $34(39.1)$ \\
\hline Other & & $2(2.45)$ & $2(2.3)$ \\
\hline
\end{tabular}

EMR, endoscopic mucosal resection

\section{Adherence to post-polypectomy guidelines}

Twelve (17\%) endoscopists stated that they did not have written polyp surveillance guidelines at their hospital. In two hospitals, the response was not consistent among endoscopists: some stated they had written guidelines, while some stated they had not. Forty-eight (71\%) endoscopists used the Norwegian guidelines for polyp surveillance. In the multivariable regression model, working at a university hospital was associated with not adhering to the Norwegian guidelines for surveillance after polypectomy, odds ratio 11.8 (95\% confidence interval (CI) $3.0-46.2, P=0.001$ ), adjusted for age, sex and experience.

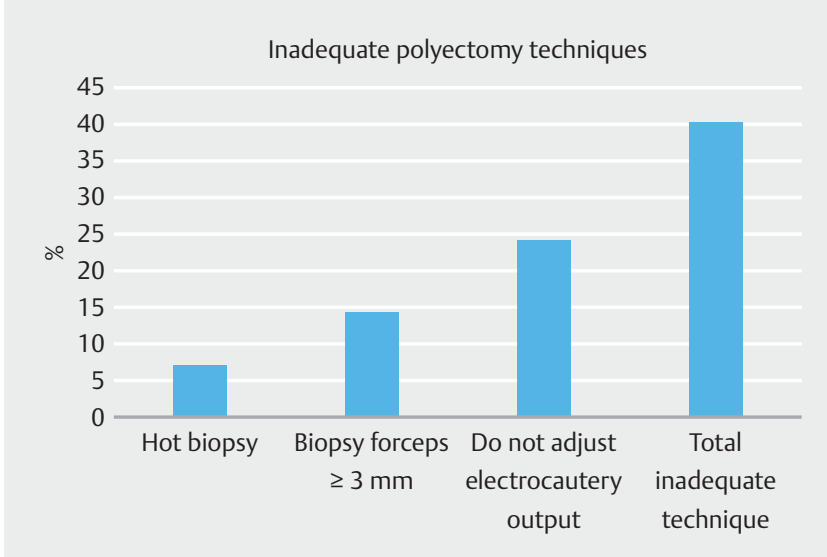

- Fig. 1 Inadequate polypectomy technique. Columns show the percentage of responders who used inadequate techniques: hot biopsy for polypectomy, biopsy forceps for removing polyps $>3 \mathrm{~mm}$ in diameter and no adjustment of electrocautery output depending on polyp size and morphology. The total is the percentage of endoscopists who used one or more of the inadequate techniques.

Thirty-seven (62\%) endoscopists had been discussing polypectomy technique as part of the department's internal education program within the last 2 years.

\section{Other measures}

Thirty (43\%) endoscopists had never performed cold snare polypectomy. Of those who used cold snare, 20 (41.7\%) did not use the recommended cold snare technique but used the same technique as in hot snare polypectomy (pull polyp towards center of lumen before cutting). Fifty-three (75.7\%) of the responders used the size of the forceps or the snare as a reference to determine polyp size, whereas $8(11.4 \%)$ estimated polyp size without any reference. Only two2 (2.9\%) of the responders used chromoendoscopy, and 33 (47.8\%) used narrow band imaging (NBI) to evaluate polyps. When removing pedunculated polyps with stalk diameter $>1 \mathrm{~cm}, 51 \%$ used detachable snares as bleeding prophylaxis and $64 \%$ used clips.

\section{Discussion}

This is the first study of polypectomy practice among Norwegian endoscopists. We found large variation in polypectomy techniques. Surprisingly, $7 \%$ of endoscopists reported that they did not remove polyps smaller than $4 \mathrm{~mm}$, and as many as $40 \%$ used one or more inadequate polypectomy techniques. One-third of endoscopists did not adhere to national guidelines for polyp surveillance.

Colorectal cancer may develop from adenomas and serrated polyps, and endoscopic examination of the colon with polypectomy has been shown to reduce CRC incidence in randomized trials $[3,4]$. Patients examined by an endoscopist who detects adenomas in a high proportion of patients have reduced risk of developing CRC compared to patients examined by endoscopists with low adenoma detection rate $[15,16]$. Currently, 
we are unable to determine which polyps have malignant potential, and therefore all should be removed. A recent literature review [17] found that $6 \%$ of adenomas between 1 and $9 \mathrm{~mm}$ in diameter progressed to advanced adenoma over a period of 2 to 3 years. Why some endoscopists ( $7 \%$ in our study) choose not to remove small polyps is not clear. It may be that some endoscopists do not remove these polyps because they are thought to be hyperplastic and of little clinical significance. In our survey, very few responders used chromoendoscopy and a little under half of the responders used NBI. Both of these could improve diagnostic accuracy. However, the ability of endoscopists to accurately separate hyperplastic polyps from adenomas using virtual biopsy technology is poor even with imagingenhancing technologies like NBI $[18,19]$.

Polypectomy to reduce CRC incidence and mortality is most effective if all adenomatous tissue is removed. It has been estimated that $27 \%$ of CRCs detected within 3 years after colonoscopy may be due to inadequate polyp removal [7]. In the present questionnaire, $14 \%$ of endoscopists used biopsy forceps when they removed polyps larger than $3 \mathrm{~mm}$ in diameter. Biopsy forceps are adequate for removal of the smallest polyps $(\leq 3 \mathrm{~mm})[6,20]$, but not for larger polyps because of the high risk of incomplete removal. In two studies, the proportion of 3and 5 -mm polyps incompletely removed using biopsy forceps was $17 \%$ and $47 \%$, respectively $[21,22]$. We had few responders using this technique, but given the compelling evidence, there should have been none. The endoscopists in our questionnaire were board-certified with long experience and serve as mentors for new endoscopists. Young fellows may therefore be trained suboptimally.

Perforation is a serious complication of polypectomy, but the frequency is less than $0.1 \%[8,23]$. Most perforations are due to use of electrocautery. Five $(7.1 \%)$ of the responders in our survey used the hot biopsy technique for polyp removal. Hot biopsy for polypectomy has been abandoned by most endoscopists due to increased risk of perforation and the burned serosa syndrome [24-26], and has been replaced with polypectomy by snaring. Recently, cold snare polypectomy (without electrocautery) has been introduced as a safe and effective technique for removing polyps smaller than $10 \mathrm{~mm}$ in diameter [27]. For removal of 4- to 6-mm polyps, only 17 responders used cold snare for polypectomy.

We found that $41.7 \%$ of endoscopists using cold snare polypectomy used the same technique as they used for hot snaring. When removing a polyp with electrocautery, it is important to pull the polyp into the colon lumen to avoid tissue damage. With the cold snare, however, one should avoid pulling the closed snare into the lumen to avoid it slipping off the polyp [28]. Some of the responders may be reluctant to use this technique because they fear more bleeding when not using electrocautery. However, post-polypectomy bleeding rates are lower with cold snare polypectomy compared to polypectomy using electrocautery [29], and risk of perforation is very small. Importantly, some studies have found that the cold snare technique is associated with a slightly lower rate of complete polyp resection than snaring with electrocautery. This may be another rea- son why many endoscopists have not endorsed cold snaring [30].

We found that $25 \%$ of our respondents do not adjust the output settings when using electrocautery. There is good evidence to support that the current should be adjusted. Different types of current (coagulation, cut or blended) have different properties and effects, including risk of complications. When removing a pedunculated polyp, one should use coagulation current in the stalk to prevent bleeding. Sessile polyps should be removed using cutting current to prevent deep tissue damage in the colon wall [28]. It is surprising that so many endoscopists in Norway do not adjust the electrocautery output, considering the risk of tissue damage. The reason is unknown, but it highlights the importance of continuous quality assurance and education to ensure patient safety and good clinical practice.

After polypectomy, guidelines recommend surveillance by colonoscopy. In Norway, new post-polypectomy surveillance guidelines were issued in 2015 by the Directorate of Health [31], and they are similar to the guidelines issued by the European Society of Gastrointestinal Endoscopy [11]. In the current study, $29 \%$ of responders did not adhere to the national guidelines. All the responders work at public hospitals or hospitals on contract with the health authorities, and one would expect that these endoscopists would be aware of, and adhere to, national guidelines. Interestingly, when we compared responders working in academic hospitals to those working in non-academic hospitals, we found that endoscopists working in university hospitals were more likely to be non-adherent to national guidelines than community-based endoscopists. The reason for this is unknown, but the result may be biased: In some hospitals, the responders were not consistent in their replies. Some endoscopists stated that they had written guidelines at their hospital, while others denied the existence of written guidelines. This discrepancy again underlines the importance of continuous quality assurance in the endoscopy unit to ensure that all endoscopists are up to date with existing routines and guidelines.

All the items discussed above show that there is need for more polypectomy training among endoscopists in Norway. Only about $60 \%$ of responders reported that there had been lectures about polypectomy technique in their internal education program during the preceding 2 years. The gastroenterology academic field in Norway has already started a training course called "The Endoscopy School," where gastroenterologists in training and specialists alike are invited to attend a course in hands-on colonoscopy under the supervision of trained instructors.

The major strength of this survey is that we invited all boardcertified gastroenterologists at 26 of 30 gastroenterological departments in Norway to participate. Therefore, we have a variety of endoscopists from all over the country, and from different types of hospitals, both university hospitals and non-university hospitals, and hospitals from both rural and urban areas. We also had almost the same sex distribution among our responders as in the register of all board-certified gastroenterol- 
ogists (18\% women and $82 \%$ men) [32]. This hopefully makes the response representative for endoscopic practice in Norway.

However, there are also limitations. Approximately $60 \%$ of those invited to participate responded to the questionnaire, and they may not be representative of all Norwegian endoscopists. Without complete response rate, there will always be a risk of selection bias. However, Johnson et al [33] found that the late responders are more like the non-responders than the early responders. When we compared the replies of the 13 late responders (defined as those who replied after the last reminder) with the 57 initial responders, there were no large differences between the two groups, but our number of respondents is small. The similarity between late-responders and initial responders might still indicate that our results may be generalizable to the whole population of Norwegian endoscopists.

\section{Conclusion}

In summary, we observed great variability in the choice of polypectomy techniques in Norway. Many endoscopists use methods that are not recommended for polyp removal, and new techniques, like cold snare polypectomy are not widely adopted. We also found that many Norwegian endoscopists do not adhere to national guidelines for surveillance after polypectomy. There is clearly a potential for improvement in the education of endoscopists, which is confirmed by the variability in practice and the high number using inadequate polypectomy techniques.

\section{Competing interests}

\section{None}

References

[1] Favoriti P, Carbone G, Greco M et al. Worldwide burden of colorectal cancer: a review. Updates Surgery 2016; 68: 7-11

[2] Svensson E, Grotmol T, Hoff G et al. Trends in colorectal cancer incidence in Norway by gender and anatomic site: an age-period-cohort analysis. Europ J Cancer Prev 2002; 11: 489-495

[3] Holme O, Loberg M, Kalager M et al. Effect of flexible sigmoidoscopy screening on colorectal cancer incidence and mortality: a randomized clinical trial. JAMA 2014; 312: 606-615

[4] Zauber AG, Winawer S], O'Brien M] et al. Colonoscopic polypectomy and long-term prevention of colorectal-cancer deaths. N Engl J Med 2012; 366: 687-696

[5] Pohl H, Srivastava A, Bensen SP et al. Incomplete polyp resection during colonoscopy-results of the complete adenoma resection (CARE) study. Gastroenterology 2013; 144: 74-80.e71

[6] Efthymiou M, Taylor AC, Desmond PV et al. Biopsy forceps is inadequate for the resection of diminutive polyps. Endoscopy 2011; 43: $312-316$

[7] Robertson DJ, Lieberman DA, Winawer S] et al. Colorectal cancers soon after colonoscopy: a pooled multicohort analysis. Gut 2014; 63: 949-956

[8] Ko CW, Dominitz JA. Complications of colonoscopy: magnitude and management. Gastrointest Endosc Clin North Am 2010; 20: 659-671
[9] Carter D, Beer-Gabel M, Zbar A et al. A survey of colonoscopic polypectomy practice amongst Israeli gastroenterologists. Ann Gastroenterol 2013; 26: 135 - 140

[10] Singh N, Harrison M, Rex DK. A survey of colonoscopic polypectomy practices among clinical gastroenterologists. Gastrointest Endosc 2004; 60: 414-418

[11] Hassan C, Quintero E, Dumonceau JM et al. Post-polypectomy colonoscopy surveillance: European Society of Gastrointestinal Endoscopy (ESGE) Guideline. Endoscopy 2013; 45: 842-851

[12] Lieberman DA, Rex DK, Winawer S] et al. Guidelines for colonoscopy surveillance after screening and polypectomy: a consensus update by the US Multi-Society Task Force on Colorectal Cancer. Gastroenterology 2012; 143: $844-857$

[13] Mulder SA, Ouwendijk RJ, van Leerdam ME et al. A nationwide survey evaluating adherence to guidelines for follow-up after polypectomy or treatment for colorectal cancer. J Clin Gastroenterol 2008; 42: $487-492$

[14] Krist AH, Jones RM, Woolf SH et al. Timing of repeat colonoscopy: disparity between guidelines and endoscopists' recommendation. Am J Prev Med 2007; 33: 471-478

[15] Corley DA, Jensen CD, Marks AR et al. Adenoma detection rate and risk of colorectal cancer and death. N Engl J Med 2014; 370: 1298 1306

[16] Kaminski MF, Regula J, Kraszewska E et al. Quality indicators for colonoscopy and the risk of interval cancer. N Engl J Med 2010; 362: $1795-1803$

[17] Vleugels JLA, Hazewinkel Y, Fockens $P$ et al. Natural history of diminutive and small colorectal polyps: a systematic literature review. Gastrointest Endosc 2017; 85: 1169-1176.e1161

[18] Kuiper T, Marsman WA, Jansen JM et al. Accuracy for optical diagnosis of small colorectal polyps in nonacademic settings. Clin Gastroenterol Hepatol 2012; 10: 1016-1020 ; quiz e1079

[19] Patel SG, Schoenfeld P, Kim HM et al. Real-time characterization of diminutive colorectal polyp histology using narrow-band imaging: implications for the resect and discard strategy. Gastroenterology 2016; 150: $406-418$

[20] Murino A, Hassan C, Repici A. The diminutive colon polyp: biopsy, snare, leave alone? Curr Opin Gastroenterol 2016; 32: 38-43

[21] Komeda Y, Kashida H, Sakurai T et al. Removal of diminutive colorectal polyps: A prospective randomized clinical trial between cold snare polypectomy and hot forceps biopsy. World J Gastroenterol 2017; 23: $328-335$

[22] Peluso F, Goldner F. Follow-up of hot biopsy forceps treatment of diminutive colonic polyps. Gastrointest Endosc 1991; 37: 604-606

[23] Ko CW, Riffle S, Michaels L et al. Serious complications within 30 days of screening and surveillance colonoscopy are uncommon. Clin Gastroenterol Hepatol 2010; 8: 166 - 173

[24] Dyer WS, Quigley EM, Noel SM et al. Major colonic hemorrhage following electrocoagulating (hot) biopsy of diminutive colonic polyps: relationship to colonic location and low-dose aspirin therapy. Gastrointest Endosc 1991; 37: 361 - 364

[25] Gilbert DA, DiMarino AJ, Jensen DM et al. Status evaluation: hot biopsy forceps. American Society for Gastrointestinal Endoscopy. Technology Assessment Committee. Gastrointest Endosc 1992; 38: 753 756

[26] Weston AP, Campbell DR. Diminutive colonic polyps: histopathology, spatial distribution, concomitant significant lesions, and treatment complications. Am J Gastroenterol 1995; 90: 24-28

[27] Ichise $Y$, Horiuchi A, Nakayama $Y$ et al. Prospective randomized comparison of cold snare polypectomy and conventional polypectomy for small colorectal polyps. Digestion 2011; 84: $78-81$

[28] Tolliver KA, Rex DK. Colonoscopic polypectomy. Gastroenterol Clin North Am 2008; 37: 229-251, ix 
[29] Horiuchi A, Nakayama Y, Kajiyama M et al. Removal of small colorectal polyps in anticoagulated patients: a prospective randomized comparison of cold snare and conventional polypectomy. Gastrointest Endosc 2014; 79: $417-423$

[30] Liu S, Ho SB, Krinsky ML. Quality of polyp resection during colonoscopy: are we achieving polyp clearance? Digest Dis Sci 2012; 57: $1786-1791$
[31] Kreft i tykktarm og endetarm - handlingsprogram. 2015: The Norwegian Directory of Health

[32] Association TNM. Oversikt over godkjente spesialister i gastroenterologi/Board certified gastroenterologists. The Norwegian Medical Association 2017

[33] Johnson TP, Wislar JS. Response rates and nonresponse errors in surveys. Jama 2012; 307: $1805-1806$ 


\section{Supplement 1}

\section{Questionnaire (answers to the questions are given in percentages in brackets)}

1. In what year were you born? Mean age 51,5 years.

2. What is your sex?
a) Male (83\%)
b) Female (17\%)

3. In what year, did you become a board-certified gastroenterologist? Mean experience 11,5 years.

4. How many colonoscopies do you perform each year, approximately?
a) $<100(10 \%)$
b) $100-300(49 \%)$
c) $>300(41 \%)$

5. How many colonoscopies have you performed during your career?
a) $<500(3 \%)$
b) $500-1000(4 \%)$
c) $1000-5000(57 \%)$
d) $5000-10000(27 \%)$
e) $>10000(9 \%)$

6 . What method do you use for determining polyp size?
a) By eye, without any reference (11\%)
b) Biopsy forceps/size of snare etc. (76\%)
c) Measure size after polypectomy and retrieval of polyp (7\%)
d) Other method. Please elaborate. (6\%)

7. What polypectomy method do you use when removing sessile polyps sized $1-3 \mathrm{~mm}$ distal to the right flexure?
a) Biopsy forceps (75\%)
b) Hot biopsy (4\%)
c) Cold snare (snare polypectomy without use of electro- cautery) (7\%)
d) Hot snare (snare polypectomy with use of electrocau- tery) (4\%)
e) EMR (snare polypectomy after submucosal fluid injec- tion) $(2 \%)$
f) I do not remove polyps of this size (4\%)
g) Other method. Please elaborate. (4\%)

8. What polypectomy method do you use when removing sessile polyps sized $4-6 \mathrm{~mm}$ distal to the right flexure?
a) Biopsy forceps (13\%)
b) Hot biopsy (3\%)
c) Cold snare (snare polypectomy without use of electro- cautery) (24\%)
d) Hot snare (snare polypectomy with use of electrocau- tery) (53\%)
e) EMR (snare polypectomy after submucosal fluid injec- tion) $(6 \%)$
f) Other method. Please elaborate. (1\%)

9. What polypectomy method do you use when removing sessile polyps sized $7-9 \mathrm{~mm}$ distal to the right flexure?
a) Biopsy forceps (0\%)
b) Hot biopsy (1\%)

c) Cold snare (snare polypectomy without use of electrocautery) (5\%)

d) Hot snare (snare polypectomy with use of electrocautery) (67\%)

e) EMR (snare polypectomy after submucosal fluid injection) $(27 \%)$

f) Other method. Please elaborate. (0\%)

10. What polypectomy method do you use when removing sessile polyps sized $1-3 \mathrm{~mm}$ proximal to the right flexure?

a) Biopsy forceps (74\%)

b) Hot biopsy (4\%)

c) Cold snare (snare polypectomy without use of electrocautery) (7\%)

d) Hot snare (snare polypectomy with use of electrocautery) (6\%)

e) EMR (snare polypectomy after submucosal fluid injection) $(2 \%)$

f) I do not remove polyps of this size (7\%)

g) Other method. Please elaborate. $(0 \%)$

11. What polypectomy method do you use when removing sessile polyps sized $4-6 \mathrm{~mm}$ proximal to the right flexure?

a) Biopsy forceps (11\%)

b) Hot biopsy (3\%)

c) Cold snare (snare polypectomy without use of electrocautery) (16\%)

d) Hot snare (snare polypectomy with use of electrocautery) (46\%)

e) EMR (snare polypectomy after submucosal fluid injection) $(21 \%)$

f) Other method. Please elaborate. (3\%)

12. What polypectomy method do you use when removing sessile polyps sized $7-9 \mathrm{~mm}$ proximal to the right flexure?

a) Biopsy forceps (0\%)

b) Hot biopsy (0\%)

c) Cold snare (snare polypectomy without use of electrocautery) $(1 \%)$

d) Hot snare (snare polypectomy with use of electrocautery) (47\%)

e) EMR (snare polypectomy after submucosal fluid injection) (49\%)

f) Other method. Please elaborate. (3\%)

13. Do you alter the size of the snare dependent on the size of the polyp?
a) Yes $(82 \%)$
b) No $(11 \%)$
c) There is only one snare size at my hospital (7\%)
d) I do not know (0\%)

14. Do you practise both cold (without use of electrocautery) and hot (with electrocautery) polypectomies?
a) Yes, I practice both methods (57\%)
b) $\mathrm{No}$, I only practice hot snare polypectomy (43\%)
c) I do not know (0\%) 
15. If "yes" in the last question: Do you choose different types of snares when performing cold (without electrocautery) than when performing hot (with electrocautery) polypectomy?
a) Yes (41\%)
b) No $(31 \%)$
c) We do not have specialized snares for cold polypectomy at my hospital (20\%)
d) I do not know (8\%)

16. If you use the cold snare polypectomy (without electrocautery) for removal of small polyps, do you use the same technique (grasping the polyp and pulling it into the lumen before closing the snare) for removal as when performing hot snare polypectomy (with electrocautery)?
a) Yes, I pull the polyp into the lumen before closing the snare (42\%)
b) No, I do not pull the polyp into the lumen before closing the snare (42\%)
c) I do not know (16\%)

17. Do you adjust the current type (cut/coagulation/blend or a pre-set program) dependent on polyp size, localisation and morphology?
a) Yes (76\%)
b) No (24\%)
c) I do not know (0\%)

18. Have you, during the last two years, used detachable snares (Endoloop or others) as a prophylactic measure against bleeding when removing stalked polyps?
a) Yes (51\%)
b) No, but there are detachable snares available at my hospital (36\%)
c) No, detachable snares are not available at my hospital $(13 \%)$
d) I do not know (0\%)

19. Have you, during the last two years, used clips on polyp stalks as a prophylactic measure against bleeding when removing stalked polyps?
a) Yes $(64 \%)$
b) No (36\%)
c) I do not know (0\%)

20. Do you take on any routine measures to prevent bleeding from stalked polyps with stalks larger than $1 \mathrm{~cm}$ in diameter? (Multiple answers possible)
a) No, I do not take on any routine measures (17\%)
b) Injection of epinephrine (31\%)
c) Clips (46\%)
d) Detachable snare (40\%)
e) Diathermy of stalk after polypectomy (13\%)
f) I do not remove polyps of this size, I refer the patients to others (4\%)
g) Other method. Please elaborate. (9\%)

21. When removing stalked polyps with snare: Where on the stalk do you place the snare?
a) The third part of the stalk nearest the polyp head (7\%)
b) The midst third part of the stalk (40\%)
c) The third part nearest the bowel wall (39\%)
d) I have no rule for where to place the snare (14\%)
e) I do not know (0\%)

22. What measures do you take on in the case of immediate bleeding after polypectomy of stalked polyps? (Multiple answers possible)
a) Injection of epinephrine (54\%)
b) Clips (91\%)
c) Argon Plasma Coagulation (6\%)
d) Coagulation the stalk with the snare (57\%)
e) Endoloop (3\%)
f) Other method. Please elaborate. (0\%)

23. What measures do you take on in the case of immediate bleeding after polypectomy of sessile polyps? (Multiple answers possible)
a) Injection of epinephrine (73\%)
b) Clips (81\%)
c) Argon Plasma Coagulation (23\%)
d) Other method. Please elaborate. (7\%)

24. Do you consider systematic injection of fluid in the submucosal space when removing sessile polyps?
a) Yes (77\%)
b) $\mathrm{No}(22 \%)$
c) I do not know (1\%)

25. If you do inject fluid into the submucosal space: What are the content(-s) of your preferred fluid? (Multiple answers possible)
a) Sodium chloride (84\%)
b) Colloid (14\%)
c) Epinephrine (43\%)
d) Dye (44\%)
e) Other. Please elaborate. (0\%)

26. If you do inject fluid into the submucosal space, is there a specific size of sessile polyps in the colon distal to the right flexure you would choose to do this?
a) No, no specific size $(27 \%)$
b) Yes, above $5 \mathrm{~mm}(18 \%)$
c) Yes, above $10 \mathrm{~mm}(13 \%)$
d) Yes, above $15 \mathrm{~mm}(13 \%)$
e) Yes, above $20 \mathrm{~mm}$ (5\%)
f) Yes, above other size. Please elaborate. (1\%)

27. If you do inject fluid into the submucosal space, is there a specific size of sessile polyps in the colon proximal to the right flexure you would choose to do this?
a) No, no specific size (24\%)
b) Yes, above $5 \mathrm{~mm}$ (34\%)
c) Yes, above $10 \mathrm{~mm}(16 \%)$
d) Yes, above $15 \mathrm{~mm}(12 \%)$
e) Yes, above $20 \mathrm{~mm}$ ( $1 \%$ )
f) Yes, above other size. Please elaborate. (1\%)

28. Do you regularly use dye spray/chromoendoscopy to investigate polyps before removal?
a) Yes (3\%)
b) No $(97 \%)$
c) I do not know (0\%) 
29. Do you regularly use NBI (Narrow Band Imaging) to investigate polyps before removal?
a) Yes $(48 \%)$
b) No $(50 \%)$
c) No, there is not NBI available at my hospital (2\%)
d) I do not know (0\%)

30. Do you find dye spray/chromoendoscopy or NBI useful for investigation of polyps?
a) Yes $(67 \%)$
b) No (16\%)
c) I do not use either chromoendoscopy nor NBI (17\%)

31. Do you use classification systems for investigation of polyps before removal? (E.g. Kudos pit pattern, NBI international colorectal endoscopic classification or others.)
a) Yes (23\%)
b) No $(71 \%)$
c) These classification systems are unknown to me (6\%)

32. Do you systematically decide not to remove polyps after investigation with chromoendoscopy or NBI?
a) Yes $(20 \%)$
b) No $(60 \%)$
c) I do not use these methods (20\%)

33. How do you normally treat polyps $>1 \mathrm{~cm}$ in size proximal to the right flexure that you suspect to be non-adenomatous (in patients with estimated life expectancy $>10$ years)?
a) Take biopsies (10\%)
b) Remove by polypectomy ( $81 \%$ )
c) Leave untreated/unbiopsied if appearance as hyperplas- tic polyp (0\%)
d) No specific routine, depends on the situation (9\%)
e) I do not know (0\%)

34. Do you regularly use chromoendoscopy/NBI to evaluate complete resection after polypectomy of sessile polyps?
a) Yes (16\%)
b) No $(84 \%)$
c) Other method. Please elaborate. (0\%)
d) I do not know (0\%)

35. Do you consider routine use of Argon Plasma Coagulation to treat the resection margins after polypectomy of sessile polyps to remove the possible polyp tissue?
a) Yes (26\%)
b) No $(55 \%)$
c) We do not have this equipment at my hospital (17\%)
d) I do not know (2\%)

36. In your opinion, are there characteristics of the assistant/ nurse that have impact on the quality of the polypectomy?

a) Yes, which nurse assisting does have an impact on the quality of the polypectomy (87\%)
b) No, which nurse assisting does not have an impact on the quality of the polypectomy ( $9 \%)$

c) I do not know (4\%)

37. If "yes" in the last questions, what characteristics of the assistant/nurse have impact, in your opinion?
a) How fast the snare is closed (28\%)
b) How firm the snare is closed? (41\%
c) Communication between endoscopist and assistant $(80 \%$
d) Other. Please elaborate. (4\%)

38. In your hospital, have you had lectures on polypectomy over the last two years?
a) Yes (62\%)
b) No $(31 \%$
c) I do not know (7\%)

39. In your hospital, do you have written guidelines for surveillance after polypectomy?
a) Yes $(81 \%)$
b) No (17\%)
c) I do not know (2\%)

40. What guidelines do you use when determining the surveillance after polypectomy in patients with estimated life expectancy $>10$ years?
a) By discretion of the endoscopist (1\%)
b) Local guidelines (10\%)
c) Norwegian guidelines (same as ESGE) (71\%)
d) British guidelines (3\%)
e) American guidelines (0\%)
f) Other guidelines. Please elaborate. (15\%) 